\title{
DESENVOLVIMENTO DA TIRIRICA (Cyperus rotundus) INFLUENCIADO pela Presença e Ausência de Palha de Cana-de-Açúcar e HERBICIDA ${ }^{1}$
}

\author{
Cyperus rotundus Development influenced by the Presence and Absence of Sugar-cane Straw \\ and Herbicide
}

\begin{abstract}
AZANIA, C.A.M. ${ }^{2}$, AZANIA, A.A.P.M. ${ }^{3}$, PAVANI, M.C.M.D. ${ }^{4}$ e ALVES, P.L.C.A. ${ }^{4}$
RESUMO - O trabalho objetivou avaliar o desenvolvimento de Cyperus rotundus plantado em diferentes profundidades na ausência e presença de imazapic e palha da cana-de-açúcar. O delineamento experimental utilizado foi inteiramente casualizado, analisado em esquema fatorial do tipo $2 \times 2 \times 6$, constituindo-se de 24 tratamentos representados pela palha (2 níveis); herbicida (2 níveis) e profundidades de plantio dos tubérculos (6 níveis). Os tratamentos foram constituídos por 25 tubérculos plantados a: 0, 2, 4, 6, 8 e $10 \mathrm{~cm}$ de profundidade, com e sem a aplicação de imazapic ( $110 \mathrm{~g} \mathrm{ha}^{-1}$ ), na condição de presença e ausência de camada de palha de cana-de-açúcar (15 t ha-1). Concluiu-se que o crescimento das manifestações epígeas foi inibido pelo herbicida somente até aos 60 dias após aplicação (DAA), na ausência e na presença da camada da palha. Nas raízes, a quantidade e viabilidade dos tubérculos foram reduzidas nos tratamentos com ausência da palha e profundidade de plantio mais superficial, na presença ou ausência da aplicação de imazapic.
\end{abstract}

Palavras-chave: Saccharum spp., planta daninha, imazapic.

\begin{abstract}
This research aimed to evaluated Cyperus rotundus development planted in different depths with and without imazapic and sugarcane straw. The experimental design was entirely randomized, analyzed in factorial outline $2 \times 2 \times 6$, being constituted of 24 treatments represented by straw (2 levels); herbicide (2 levels) and planting depth (6 levels). The treatments were constituted by 25 tubers planted in $0,2,4,6,8$ and $10 \mathrm{~cm}$ depths with and without imazapic (110 $\left.\mathrm{g} \mathrm{ha}^{-1}\right)$ and sugarcane straw (15 $\left.\mathrm{t} \mathrm{ha}^{-1}\right)$. The shoots were inhibited only until 60 days after imazapic application with and without sugarcane straw. The roots, tubers quantity and viability were reduced by treatments with straw absence and planted tubers in $0 \mathrm{~cm}$ superficial depth in presence or absence imazapic application.
\end{abstract}

Keywords: Saccharum spp., weed, imazapic.

\section{INTRODUÇÃO}

A queima pré-colheita da cana-de-açúcar é prática usual entre os produtores, que a utilizam principalmente para eliminar grande parte da palha e afugentar animais peçonhentos, facilitando a colheita. Entretanto, segundo
Martins et al. (1999), em função de leis ambientais, para melhoria da qualidade do ar nas cidades próximas às áreas canavieiras, a queima da cana-de-açúcar está proibida no Estado de São Paulo até o ano de 2012 (Decreto - lei - no 41.719 de 16.7.1997 e no 45.056 de 17.9.1997).

Recebido para publicação em 18.4.2005 e na forma revisada em 24.2.2006.

2 Pqc do Centro de Cana IAC, Caixa postal 206, 14001-970 Ribeirão Preto-SP. ${ }^{3}$ Doutoranda em Produção Vegetal da Universidade Estadual Paulista - FCAVJ/UNESP, Via de acesso Paulo Donato Castellane, s/n, 14844-900 Jaboticabal-SP; ${ }^{4}$ Prof. D.S. do Dep. de Biologia Aplicada à Agropecuária - FCAVJ/UNESP. 
Assim, as áreas com colheita de cana crua tendem a aumentar e, conseqüentemente, haverá mais áreas com palha depositada sobre o solo. Essa camada de palha deixada nas áreas de cana-de-açúcar colhida sem a prévia queima do canavial pode superar $20 \mathrm{t} \mathrm{ha}^{-1}$ (Velini \& Negrisoli, 2000) e proporcionar estímulo à germinação e ao desenvolvimento de algumas espécies e redução de outras (Martins et al., 1999).

Essas situações podem ocorrer pelo fato de a cobertura morta proporcionar temperaturas com menores oscilações, além de alterações na quantidade de radiação solar e qualidade do comprimento de ondas luminosas sobre a superfície do solo (Taylorson \& Borthwick, 1969; Fener, 1980). Todavia, essas mesmas situações tornam-se indiferentes para espécies como Cyperus rotundus, que não apresentam as brotações e manifestações epígeas totalmente inibidas ou estimuladas pela camada de palha (Durigan, 2000). Nesse caso, Durigan et al. (2004) observaram que a camada de palha correspondente a $10 \mathrm{t} \mathrm{ha}^{-1}$ reduziu a infestação, mas não evitou grandes densidades de $C$. rotundus.

Cyperus rotundus é uma planta daninha de ciclo fotossintético $\mathrm{C} 4$, o que possibilita maior eficiência na absorção de $\mathrm{CO}_{2}$ atmosférico, favorecendo a sobrevivência e agressividade da planta (Elmore \& Paul, 1983; Wills, 1987). Segundo Lorenzi (1983), sua agressividade é tamanha que, em condições edafoclimáticas favoráveis, pode produzir até 3.000 tubérculos $\mathrm{m}^{-2}$ com mais de 2.000 manifestações epígeas $\mathrm{m}^{-2}$, as quais, quando capinadas, podem crescer de um a três centímetros por dia. Em condições similares de elevada temperatura e umidade, o plantio de um único tubérculo é suficiente para formar outros 10 tubérculos em 60 dias (Magalhães, 1965).

Portanto, devido à agressividade e rusticidade de $C$. rotundus, seu controle é muito difícil. Entre os métodos de controle, Glaze (1987) citou a luz e as elevadas temperaturas na superfície do solo, por causarem a morte dos bulbos basais e dos tubérculos por desidratação.

Um outro método de controle muito utilizado é o químico; para seu uso existem diversos herbicidas registrados no Brasil. Nesse caso,
Durigan (1991) relatou que o menor número e a produção de tubérculos são os melhores resultados que um herbicida pode proporcionar. Contudo, no controle químico a camada de palha pode prejudicar a ação do herbicida aplicado, pois, de acordo com Velini \& Negrisoli (2000), uma camada de palha de 10 e $15 \mathrm{t} \mathrm{ha}^{-1}$ pode interceptar aproximadamente 99,4 e $99,5 \%$ da calda aplicada, respectivamente.

Dessa forma, considerando as influências da camada de palha sobre a comunidade infestante, a agressividade e o difícil controle de $C$. rotundus, este trabalho objetivou avaliar o desenvolvimento dessa espécie plantada na ausência e na presença de palha da cana-deaçúcar, em diferentes profundidades, com e sem aplicação de imazapic.

\section{MATERIAL E MÉTODOS}

O trabalho foi desenvolvido na Faculdade de Ciências Agrárias e Veterinárias de Jaboticabal-UNESP, em área experimental de campo pertencente ao Departamento de Biologia Aplicada à Agropecuária, em vasos de plástico com capacidade de $12 \mathrm{~L}$. O substrato usado no preenchimento foi preparado na proporção $2: 1: 1$, sendo terra de textura argilosa, areia e esterco de curral, respectivamente.

Em cada vaso foram plantados 25 tubérculos de tiririca previamente selecionados de acordo com o peso, que sempre permaneceu entre 25 e 30 g. Cada grupo de 25 tubérculos previamente selecionados foi plantado na mesma profundidade em um mesmo vaso. A partir do lote de tubérculos foram escolhidos casualmente 100 deles, que, após serem submetidos à solução de tetrazólio $1 \%$ por 48 horas, apresentaram 96\% de viabilidade. Os vasos foram irrigados o suficiente para garantir o desenvolvimento dos tubérculos e das manifestações epígeas.

Os tratamentos foram constituídos pela combinação entre a presença e a ausência de palha e herbicida, além das profundidades de plantio dos tubérculos. Assim, foram obtidas as condições: com palha e sem herbicida $(\mathrm{CPSH})$, com palha e herbicida $(\mathrm{CPCH})$, sem palha e sem herbicida (SPSH) e sem palha e com herbicida ( $\mathrm{SPCH}$ ), em todas as 
profundidades de plantio. Essas profundidades constituíram-se de superfície do solo (P0) e a $2 \mathrm{~cm}$ (P2), $4 \mathrm{~cm}$ (P4), $6 \mathrm{~cm}$ (P6), $8 \mathrm{~cm}$ (P8) e $10 \mathrm{~cm}(\mathrm{P} 10)$.

A camada de palha utilizada sobre os vasos foi de cana-de-açúcar, cultivar SP80-1811, correspondente a $15 \mathrm{t} \mathrm{ha}^{-1}$. O herbicida utilizado foi o imazapic (110 g ha-1). Na aplicação do herbicida utilizou-se equipamento costal pressurizado $\left(\mathrm{CO}_{2}\right)$, munido de barra com três bicos Teejet DG 110.02VS, espaçados de $0,50 \mathrm{~m}$, que, trabalhando a uma pressão de 35 libras pol $^{-2}$, proporcionou volume de calda de $250 \mathrm{~L} \mathrm{ha}^{-1}$. No momento da aplicação o dia estava ensolarado, com ausência de nuvens, ventos entre 3 e $4 \mathrm{~km} \mathrm{~h}^{-1}$ e temperatura do solo a $10 \mathrm{~cm}$ de profundidade de $26,6 \mathrm{e}$ $22,7^{\circ} \mathrm{C}$, na ausência e presença de palha, respectivamente.

O delineamento experimental utilizado foi inteiramente casualizado, analisado em esquema fatorial do tipo $2 \times 2 \times 6$, constituindose de 24 tratamentos, representados pela palha (dois niveis), pelo herbicida (dois níveis) e pelas profundidades de plantio dos tubérculos (seis niveis).

A análise de variância pelo teste $F$ foi utilizada para avaliar o efeito dos tratamentos sobre as variáveis; posteriormente, para comparação das médias dos tratamentos, utilizou-se o teste de Tukey a $5 \%$ de probabilidade.

O percentual de cobertura do solo pela tiririca foi analisado aos 10, 60 e 130 dias após aplicação (DAA) do herbicida, sendo atribuídas notas percentuais, utilizando-se uma escala variando de 0 a $100 \%$, sendo $0 \%$ nenhuma tiririca sobre o vaso e $100 \%$ toda a área do vaso coberta por tiririca. Avaliou-se também a massa seca aos 130 DAA. Para isso, procedeuse, após a coleta, à lavagem e secagem, em estufa de circulação forçada $\left(60{ }^{\circ} \mathrm{C}\right)$ até peso constante, de toda a parte aérea da tiririca existente sobre cada parcela.

Avaliou-se em cada parcela, aos 130 DAA,o número dos tubérculos, bem como a viabilidade destes, escolhendo-se casualmente 25 tubérculos e submetendo-os à solução de tetrazólio $1 \%$ por 48 horas. A massa seca dos tubérculos de cada parcela também foi avaliada.

\section{RESULTADOS E DISCUSSÃO}

Na ausência da camada de palha, o percentual de cobertura das manifestações epígeas em todas as profundidades de plantio foi reduzido pelo herbicida, principalmente na avaliação realizada aos 10 DAA (Figura 1). À medida que o tempo transcorreu, esses percentuais de cobertura foram aumentando; aos 60 DAA alguns tratamentos herbicidas já apresentavam até $40 \%$ de cobertura (Figura 1). Nesse período, dos 10 aos 60 DAA, foi mais perceptível a diferença entre os percentuais de cobertura dos tratamentos testemunha e herbicida.

Esses resultados corroboram aqueles descritos por Durigan et al. (2004), ao constatarem que o imazapic (105 $\left.\mathrm{g} \mathrm{ha}^{-1}\right)$, além de ser seletivo à cana-de-açúcar, apresentou melhor controle sobre as manifestações epígeas também na ausência da camada de palha.

Aos 130 DAA, o percentual de cobertura manteve-se reduzido apenas para os tubérculos plantados na superfície do solo (PO) tratados com o herbicida, enquanto nas demais profundidades os percentuais de cobertura foram superiores a $60 \%$, ficando muito próximos daqueles das testemunhas (Figura 1). O menor percentual de cobertura para os tubérculos plantados na superfície pode ter sido causado pela combinação entre a ação direta do herbicida sobre os tubérculos e, segundo Glaze (1987), a ação direta do sol e as elevadas temperaturas.

Nessa mesma condição de ausência da camada de palha, a testemunha apresentou os maiores percentuais de cobertura em todas as profundidades e épocas de avaliação, exceto os tubérculos plantados na superfície (P0) aos 10 DAA. Entretanto, nas demais avaliações, esses tubérculos recuperaram-se e apresentaram percentuais de cobertura superiores a $40 \%$, porém menores que aqueles das demais profundidades de plantio (Figura 1).

A presença da camada de palha não interferiu no percentual de cobertura das manifestações epígeas nos tratamentos com o herbicida, que, embora reduzido nas primeiras avaliações mais próximas à aplicação, aumentou gradativamente com o transcorrer do tempo (Figura 1). Contudo, a partir dos

Planta Daninha, Viçosa-MG, v. 24, n. 1, p. 29-35, 2006 
60 DAA observou-se que, mesmo nos tratamentos com herbicida, os tubérculos plantados na superfície do solo (P0) apresentaram percentual de cobertura da parte aérea próximo a $30 \%$, enquanto na condição de ausência de palha foi próximo de 5\% (Figura 1). Esses resultados sugerem que parte do herbicida pode ter ficado retida na palha, suficientemente para não prejudicar o crescimento das manifestações epígeas na profundidade PO na presença de palha. Nesse sentido, Velini \& Negrisoli (2000) relataram que uma camada de palha de $1 \mathrm{t} \mathrm{ha}^{-1}$ permite que apenas $35,5 \%$ da calda pulverizada atinja a superfície do solo. Essa interceptação da calda aumenta para 99,5\% nas camadas de palha com densidade de $15 \mathrm{t} \mathrm{ha}^{-1}$. No entanto, nos trabalhos de Hernandez et al. (2001) e Rodrigues (1993) não foi constatada retenção pela palha quando foram utilizados imazapic e imazaquin, respectivamente.
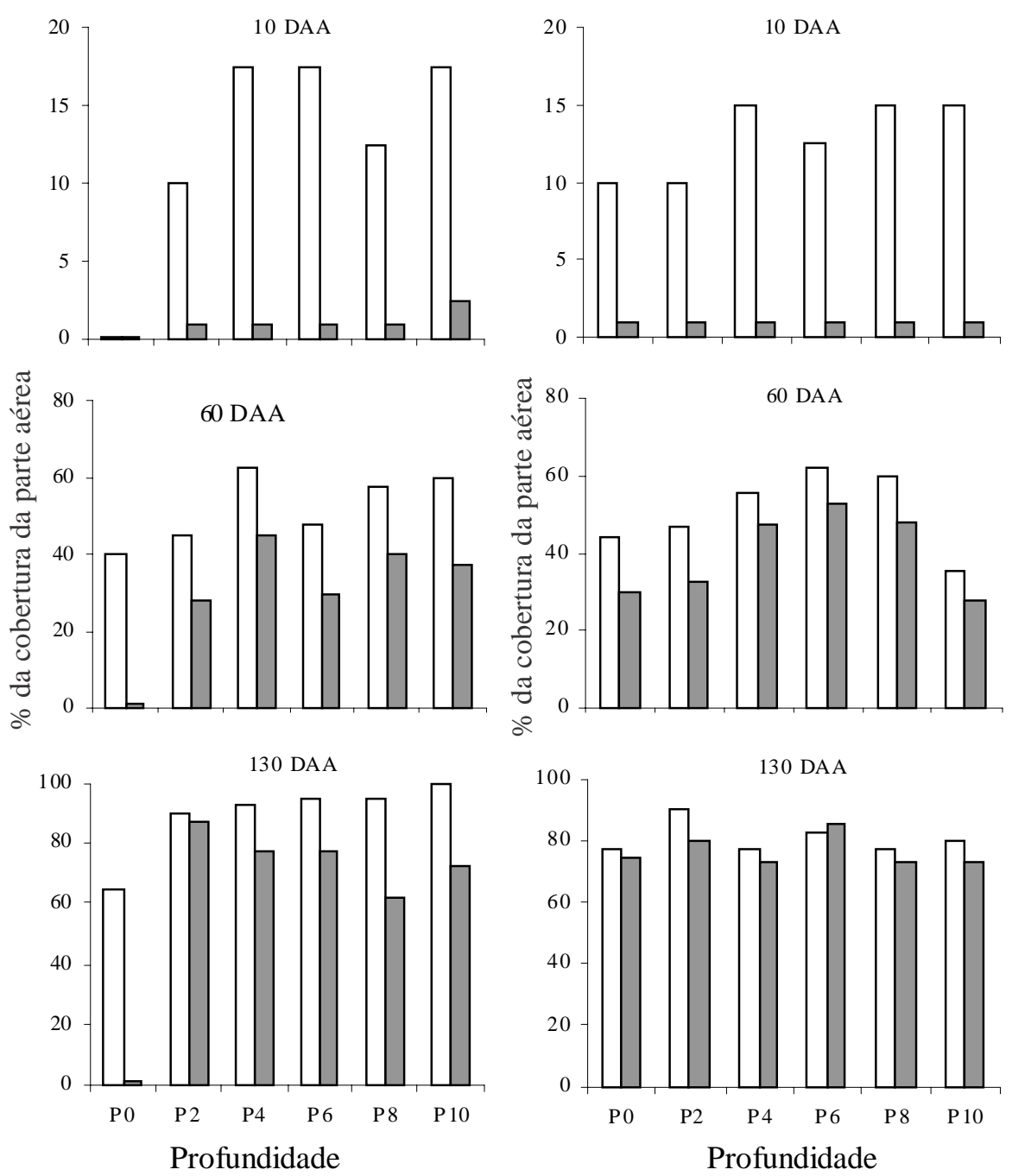

Palha $\left(0 \mathrm{t} \mathrm{ha}^{-1}\right)$

Palha $\left(15 \mathrm{tha}^{-1}\right)$

$\square$ testemunha $\quad \square$ imazapic $\left(110 \mathrm{~g} \mathrm{ha}^{-1}\right) \quad$ DAA(dias após aplicação)

superfície do solo (P0), $2 \mathrm{~cm}(\mathrm{P} 2), 4 \mathrm{~cm}(\mathrm{P} 4), 6 \mathrm{~cm}(\mathrm{P} 6), 8 \mathrm{~cm}$ (P8), $10 \mathrm{~cm}(\mathrm{P} 10)$

Figura 1 - Porcentagem de cobertura das manifestações epígeas de Cyperus rotundus plantadas em diferentes profundidades, na presença e ausência de camada de palha de cana-de-açúcar e imazapic. 
A disparidade existente entre os dados observados e aqueles da literatura pode ser explicada pelo tipo de irrigação utilizada. No experimento, a irrigação foi apenas para garantir o desenvolvimento dos tubérculos e das manifestações epígeas. No entanto, essa menor quantidade de água pode ter contribuído para a retenção do herbicida na palha. Essa possível retenção do imazapic também foi observada por Azania et al. (2004), quando aplicaram o herbicida sobre a camada de palha de cana-de-açúcar na cultura do amendoim.

Na Figura 1, mesmo na presença da palha, constata-se que até os 60 DAA o percentual de cobertura foi reduzido pelo herbicida, mas aos 130 DAA, em todas as profundidades, as coberturas pelas manifestações epígeas também foram superiores a $60 \%$, ficando ainda mais próximas dos percentuais das testemunhas. Nestas, mesmo os tubérculos plantados na superfície (PO) resultaram em percentual de cobertura próximo de 10\%, aos 10 DAA, e superior a $40 \%$, a partir dos 60 DAA. Esse comportamento possivelmente seja atribuído à menor incidência solar diretamente sobre os tubérculos e à maior umidade na camada superficial do solo, proporcionada pela palha (Glaze, 1987).

Os percentuais de cobertura, aos 130 DAA, superiores a $60 \%$ para os tratamentos na ausência e presença do herbicida e da camada de palha foram constituídos por manifestações epígeas vigorosas (Figura 1). Contudo, a massa seca da parte aérea foi reduzida nos tratamentos que envolveram o herbicida (Tabela 1) e também naqueles que envolveram a ausência de palha com os tubérculos plantados na superfície (Tabela 2). Nesse caso, possivelmente, a exposição à incidência da luz solar tem conseqüente prejuízo das manifestações epígeas.

O número de tubérculos aos 130 DAA foi a variável em que as maiores reduções ocorreram nos tratamentos que envolveram ausência da palha, presença de herbicidas e naqueles de profundidade de plantio superficial (Tabela 1).

Tabela 1 - Número, massa seca, viabilidade dos tubérculos e massa seca da parte aérea de plantas de tiririca plantadas na ausência e presença de camada de palha de cana-de-açúcar e imazapic, em diferentes profundidades

\begin{tabular}{|c|c|c|c|c|}
\hline \multirow{2}{*}{ Característica } & \multicolumn{2}{|c|}{ Tubérculo } & \multicolumn{2}{|c|}{ Parte aérea } \\
\hline & Número & Massa seca & Viabilidade $^{1 /}$ & Massa seca \\
\hline \multicolumn{5}{|l|}{ Palha (A) $-t^{-1} a^{-1}$} \\
\hline 0 & $233,73 \mathrm{~b}$ & $28,85 \mathrm{~b}$ & $9,26 \mathrm{a}$ & $15,39 \mathrm{a}$ \\
\hline 15 & $272,71 \mathrm{a}$ & $39,01 \mathrm{a}$ & $9,62 \mathrm{a}$ & $16,40 \mathrm{a}$ \\
\hline \multicolumn{5}{|l|}{ Imazapic (B) $\mathrm{g} \mathrm{ha}^{-1}$} \\
\hline 0 & 298,33 a & $38,92 \mathrm{a}$ & $9,63 \mathrm{a}$ & $18,02 \mathrm{a}$ \\
\hline 110 & $208,10 \mathrm{~b}$ & $28,94 \mathrm{~b}$ & $9,25 \mathrm{~b}$ & $13,77 \mathrm{~b}$ \\
\hline \multicolumn{5}{|l|}{ Profundidade $(\mathrm{C}) \mathrm{cm}$} \\
\hline 0 & $182,44 \mathrm{~b}$ & $27,13 \mathrm{~b}$ & $8,60 \mathrm{~b}$ & $13,34 \mathrm{a}$ \\
\hline 2 & 287,06 a & $33,85 \mathrm{ab}$ & $9,67 \mathrm{a}$ & $15,68 \mathrm{a}$ \\
\hline 4 & $287,63 \mathrm{a}$ & $35,95 \mathrm{a}$ & $9,69 \mathrm{a}$ & $16,90 \mathrm{a}$ \\
\hline 6 & $266,25 \mathrm{a}$ & $33,82 \mathrm{ab}$ & $9,47 \mathrm{ab}$ & $16,82 \mathrm{a}$ \\
\hline 8 & $246,56 \mathrm{a}$ & $36,13 \mathrm{a}$ & $9,63 \mathrm{a}$ & 15,86 a \\
\hline 10 & $249,38 \mathrm{a}$ & $36,70 \mathrm{a}$ & $9,59 \mathrm{a}$ & $16,76 \mathrm{a}$ \\
\hline \multicolumn{5}{|l|}{$\mathrm{F}$} \\
\hline Palha (A) & $16,17 * *$ & $46,38^{* * *}$ & $3,82 \mathrm{NS}$ & $1,69 \mathrm{NS}$ \\
\hline Imazapic (B) & (36,66**; & $44,76^{* *}$ & $4,20^{*}$ & $29,90 * *$ \\
\hline Profundidades (C) & $10,74 * *$ & $3,76^{* *}$ & $3,36^{* *}$ & $2,03 \mathrm{NS}$ \\
\hline AXB & 4,21* & $1,79 \mathrm{NS}$ & $3,47 \mathrm{NS}$ & $1,84 \mathrm{NS}$ \\
\hline $\mathrm{AXC}$ & $3,82 * *$ & $0,61 \mathrm{NS}$ & $3,41 * *$ & $4,06 * *$ \\
\hline $\mathrm{BXC}$ & $3,01 *$ & $1,53 \mathrm{NS}$ & $3,98^{* *}$ & $1,16 \mathrm{NS}$ \\
\hline $\mathrm{AXBXC}$ & $0,09 \mathrm{NS}$ & $0,52 \mathrm{NS}$ & $4,38 * *$ & $1,02 \mathrm{NS}$ \\
\hline $\mathrm{CV}(\%)$ & 18,75 & 21,55 & 9,68 & 23,94 \\
\hline
\end{tabular}

${ }^{1 /}$ Dados transformados em arc sen $\sqrt{D \square 0,5} ; *$ significativo a $5 \%$ de probabilidade; ** significativo a $1 \%$ de probabilidade; NS - não-significativo. Médias seguidas de mesma letra, na coluna, não diferem estatisticamente entre si. 
Tabela 2 - Desdobramento das interações A x C (palha x profundidades) e B x C (imazapic x profundidades) para número, viabilidade de tubérculos e massa seca da parte aérea de plantas de tiririca

\begin{tabular}{|c|c|c|c|c|c|c|c|}
\hline \multicolumn{8}{|c|}{ Interação palha $(\mathrm{A})-\mathrm{t} \mathrm{ha}^{-1} \mathrm{x}$ profundidades $(\mathrm{C})-\mathrm{cm}$} \\
\hline \multirow{2}{*}{ Variável } & \multirow{2}{*}{$\begin{array}{c}\mathrm{A} \\
\left(\mathrm{t} \mathrm{ha}^{-1}\right)\end{array}$} & \multicolumn{6}{|c|}{$\mathrm{C}(\mathrm{cm})$} \\
\hline & & 0 & 2 & 4 & 6 & 8 & 10 \\
\hline \multirow{2}{*}{$\begin{array}{l}\text { Número de } \\
\text { tubérculos }\end{array}$} & 0 & $117,25 \mathrm{Bb}$ & $268,12 \mathrm{Aa}$ & $284,50 \mathrm{Aa}$ & $250,13 \mathrm{Aa}$ & $240,25 \mathrm{Aa}$ & $242,13 \mathrm{Aa}$ \\
\hline & 15 & $247,63 \mathrm{Aa}$ & $306,00 \mathrm{Aa}$ & $290,75 \mathrm{Aa}$ & $282,38 \mathrm{Aa}$ & $252,88 \mathrm{Aa}$ & $256,63 \mathrm{Aa}$ \\
\hline \multirow{2}{*}{$\begin{array}{l}\text { Viabilidade de } \\
\text { tubérculos }^{1 /}\end{array}$} & 0 & $7,56 \mathrm{Bb}$ & $6,69 \mathrm{Aa}$ & $9,67 \mathrm{Aa}$ & $9,37 \mathrm{Aa}$ & $9,69 \mathrm{Aa}$ & $9,56 \mathrm{Aa}$ \\
\hline & 15 & $9,64 \mathrm{Aa}$ & $9,64 \mathrm{Aa}$ & $9,72 \mathrm{Aa}$ & $9,56 \mathrm{Aa}$ & $9,56 \mathrm{Aa}$ & $9,61 \mathrm{Aa}$ \\
\hline \multirow{2}{*}{$\begin{array}{l}\text { Massa seca da } \\
\text { parte aérea }\end{array}$} & 0 & $9,11 \mathrm{Bb}$ & $14,86 \mathrm{Aa}$ & $17,78 \mathrm{Aa}$ & $17,21 \mathrm{Aa}$ & $16,02 \mathrm{Aa}$ & $17,36 \mathrm{Aa}$ \\
\hline & 15 & $17,58 \mathrm{Aa}$ & $16,50 \mathrm{Aa}$ & $16,03 \mathrm{Aa}$ & $16,43 \mathrm{Aa}$ & $15,70 \mathrm{Aa}$ & $16,17 \mathrm{Aa}$ \\
\hline \multicolumn{8}{|c|}{ Interação imazapic (B) $-\mathrm{g} \mathrm{ha}^{-1} \mathrm{x}$ profundidades $(\mathrm{C})-\mathrm{cm}$} \\
\hline \multirow{2}{*}{ Variável } & $\mathrm{B}$ & \multicolumn{6}{|c|}{$\mathrm{C}(\mathrm{cm})$} \\
\hline & $\left(\mathrm{g} \mathrm{ha}^{-1}\right)$ & 0 & 2 & 4 & 6 & 8 & 10 \\
\hline \multirow{2}{*}{$\begin{array}{l}\text { Número de } \\
\text { tubérculos }\end{array}$} & 0 & $256,63 \mathrm{Ab}$ & $337,75 \mathrm{Aa}$ & $308,62 \mathrm{Aab}$ & $287,38 \mathrm{Aab}$ & $298,75 \mathrm{Aab}$ & $300,88 \mathrm{Aab}$ \\
\hline & 125 & $108,25 \mathrm{Bc}$ & $236,38 \mathrm{Bab}$ & $266,63 \mathrm{Aa}$ & '245,13 Aab & $194,38 \mathrm{Bb}$ & $197,88 \mathrm{Bab}$ \\
\hline \multirow{2}{*}{$\begin{array}{l}\text { Viabilidade de } \\
{\text { tubérculos }{ }^{1 /}}^{1 /}\end{array}$} & 0 & $9,72 \mathrm{Aa}$ & $9,67 \mathrm{Aa}$ & $9,69 \mathrm{Aa}$ & $9,54 \mathrm{Aa}$ & $9,67 \mathrm{Aa}$ & $9,51 \mathrm{Aa}$ \\
\hline & 110 & $7,49 \mathrm{Bb}$ & $9,67 \mathrm{Aa}$ & $9,69 \mathrm{Aa}$ & 9,40 Aa & 9,59 Aa & $9,67 \mathrm{Aa}$ \\
\hline
\end{tabular}

Médias seguidas pela mesma letra minúscula, na linha, e pela mesma letra maiúscula, na coluna, não diferem estatisticamente pelo teste de Tukey a $5 \%$ de probabilidade. ${ }^{1 /}$ Dados transformados em arc sen $\sqrt{D \square 0,5}$.

A quantidade de tubérculos foi reduzida pelos tratamentos com ausência de palha e presença de herbicida, independentemente da profundidade de plantio (Tabela 3). Nesse caso, o herbicida não teve a palha como barreira física, ficando em contato direto com os tubérculos, especialmente aqueles da profundidade de plantio mais superficial, conforme se observa na interação herbicidas e profundidades (Tabela 2).

O não-prejuízo ao número de tubérculos nos tratamentos que envolveram a camada de palha também foi observado por Silva et al. (2003), quando não constataram redução no número de tubérculos em tratamentos envolvendo camada de palha com densidade de $16 \mathrm{t} \mathrm{ha}^{-1}$.

Tabela 3 - Desdobramento da interação palha (A) x imazapic (B) para o número de tubérculos de plantas de tiririca

\begin{tabular}{|c|c|c|c|}
\hline \multirow{2}{*}{ Variável } & \multirow{2}{*}{$\begin{array}{c}\mathrm{A} \\
\left(\mathrm{t} \mathrm{ha}^{-1}\right)\end{array}$} & \multicolumn{2}{|c|}{ B (g i.a. ha $\left.{ }^{-1}\right)$} \\
\hline & & 0 & 110 \\
\hline \multirow{2}{*}{$\begin{array}{l}\text { Número de } \\
\text { tubérculos }\end{array}$} & 0 & $288,79 \mathrm{Aa}$ & $178,67 \mathrm{Bb}$ \\
\hline & 15 & $307,88 \mathrm{Aa}$ & $237,54 \mathrm{Ab}$ \\
\hline
\end{tabular}

Médias seguidas pela mesma letra minúscula, na linha, e pela mesma letra maiúscula, na coluna, não diferem estatisticamente pelo teste de Tukey a $5 \%$ de probabilidade.
Outro fator que determinou o prejuízo do número de tubérculos possivelmente tenha sido a maior incidência de luz solar sobre aqueles plantados na superfície do solo. De acordo com a interação palha e profundidades (Tabela 2), pode ser observada quantidade inferior e bastante considerável de tubérculos no tratamento em que estes foram plantados na superfície do solo e na ausência de palha.

A viabilidade dos tubérculos foi prejudicada também nos tratamentos que envolveram a ausência da palha e a profundidade de plantio mais superficial (Tabela 2). A incidência maior de luz solar sobre os tubérculos, possivelmente, tenha causado a morte por desidratação de parte dos tubérculos. Entretanto, esse tratamento proporcionou também a maior exposição dos tubérculos ao herbicida, conforme se observa na interação herbicidas e profundidades (Tabela 2).

Pode-se constatar que o desenvolvimento da parte aérea da tiririca até os 60 DAA foi inibido pelos tratamentos que envolveram o herbicida, independentemente das profundidades e da presença de palha. No entanto, aos 130 DAA a cobertura ocasionada pelas manifestações epígeas foi superior a $60 \%$, exceto o tratamento com herbicida na profundidade mais superficial de plantio e na ausência de 
palha. Nas raízes, a quantidade e viabilidade de tubérculos foram menores na ausência da palha e na profundidade de plantio mais superficial, independentemente da presença ou ausência do herbicida.

\section{LITERATURA CITADA}

AZANIA, C. A. M. et al. Seletividade de imazapic para dois cultivares de amendoim (Arachis hypogaea) cultivados na ausência e na presença de palha de cana-de-açúcar. Planta Daninha, v. 22, n. 1, p. 145-150, 2004.

DURIGAN, J. C. Integração de métodos mecânico e químico para o controle de tiririca (Cyperus rotundus L.). Científica, v. 28 , n. $1 / 2$, p. $87-101,2000$.

DURIGAN, J. C. Manejo da tiririca (Cyperus rotundus) antes e durante a implantação da cultura de cana-de-açúcar (Saccharum spp.). 1991. 336 f. Tese (Livre Docência) Universidade Estadual Paulista, Jaboticabal, 1991.

DURIGAN, J. C. et al. Controle químico da tiririca (Cyperus rotundus), com e sem cobertura do solo pela palha de canade-açúcar. Planta Daninha, v. 22, n. 1, p. 127-135, 2004.

ELMORE, C. D.; PAUL, R. N. Composite list of $\mathrm{C}_{4}$ weeds. Weed Sci., v. 1, n. 5, p. 686-692, 1983.

FENER, M. Germination tests of thirty-two East African weed species. Weed Res., v. 20, p. 135-138, 1980.

GLAZE, N. C. Cultural and mechanical manipulation of Cyperus spp. Weed Technol., v. 1, n. 1, p. 82-83, 1987.

HERNANDEZ, D. D. et al. Influência do resíduo de colheita de cana-de-açúcar sem queima sobre a eficiência dos herbicidas imazapic e imazapic + pendimenthalin. Planta Daninha, v. 19, n. 3, p. 419-426, 2001.
LORENZI, H. Plantas daninhas e seu controle na cultura da cana-de-açúcar. In: REUNIÃO TÉCNICA AGRONÔMICA, 1983, Piracicaba. Anais... Piracicaba: Copersucar, 1983. p. $58-73$.

MAGALHÃES, A. C. Influência do teor de umidade no tubérculo e da quantidade de água disponível no solo sobre a capacidade de brotação da tiririca. Bragantia, v. 24, n. 37 , p. 507-513, 1965.

MARTINS, D. et al. Emergência em campo de dicotiledôneas infestantes em solo coberto com palha de cana-de-açúcar. Planta Daninha, v. 17, n. 1, p. 151-161, 1999.

RODRIGUES, B. N. Influência da cobertura morta no comportamento dos herbicidas imazaquin e clomazone. Planta Daninha, v. 11, n. 1, p. 21-28, 1993.

SILVA, J. R. V.; COSTA, N. V.; MARTINS, D. Efeito da palha de cultivares de cana-de-açúcar na emergência de Cyperus rotundus. Planta Daninha, v. 21, n. 3, p. 375-380, 2003.

TAYLORSON, R. B.; BORTHWICK, H. A. A. Light filtration by foliar canopies: significance for light-controlled weed seed germination. Weed Sci., v. 17, n. 1, p. 48-51, 1969.

VELINI, E. D.; NEGRISOLI, E. Controle de plantas daninhas em cana crua. In: CONGRESSO BRASILEIRO DA CIÊNCIA DAS PLANTAS DANINHAS, 22., 2000, Foz do Iguaçu. Palestras... Foz do Iguaçu: 2000. p. $148-164$.

WILLS, G. D. Description of purple and yellow nutsedge (Cyperus rotundus and C. esculentus). Weed Technol., v. 1, n. 1, p. 2-9, 1987. 